\title{
Multicultural Teaching in Regions (Within Sustainability Conception in Education)
}

Tatiana Zhukova, ${ }^{+*}$ Vladimir Bogoslovskiy, ${ }^{*}$ Tatiana Dobudko, ${ }^{\dagger}$ Svetlana Sevenyuk ${ }^{\dagger}$ and Lidiya Vershinina $^{\dagger}$

\section{Abstract}

This research is dedicated to the study of the sustainability conception in education adopted by multicultural processes. The results of this research are analysed from a study conducted at Samara State University of Social Sciences and Education and Ludwigsburg Pedagogical Institute.

Multicultural teaching develops dynamically. It seems possible to develop an instrument to evaluate on an ongoing basis as to how to improve multicultural teaching further within regional policy. For this, we aim to demonstrate the importance of using Inter- and trans-disciplinary methods as a significant contributor in many countries to better understand perspectives to analyse multicultural teaching in regions. To further the ideas about the perspectives to develop multicultural teaching, we feel strongly that action-oriented and reflective and responsible methods are an important mediator to ensure multicultural teaching. Hence, in this research we speak about the integrative model, in particular, considering the relationship that exists between the educational practices to increase the role of education and the determinate needs of peoples of all nationalities and the new phenomenon of the regional policy. To do so, we use structural and functional approach. The ideas presented here attempt to visually organise the views upon which Russian intercultural experts have reached in particular considering the methods that exist to improve multicultural teaching.

Keywords: Sustainability Conception; Multicultural Education, Multicultural Teaching Model, Integration

\footnotetext{
+ Samara State Pedagogical University of Social Sciences and Education,

${ }^{*}$ Corresponding Author, Email: tatiana2hukova@yandex.ru

${ }^{¥}$ Herzen State Pedagogical University
} 


\section{Introduction}

From an academic perspective, it is interesting to assess how the sustainability conception has adjusted to the change within multiculturalism. It is interesting to note here that none of the notions-multicultural teaching and sustainability conception in education has been considered together.

Nowadays, the lack of systemic or unified research in the field of multicultural teaching in different countries has reduced knowledge to the simple implementation of individual different training courses in different regions of the country (Biserova \& Shagivaleeva 2019; Burns \& Welch, 2018; Duzhakova, 2008; Fayzullina, 2019). As a result, multicultural teaching is more oriented only towards the needs and the views of a country, rather than towards a system of multicultural interests that consider the interests of regions with the multicultural background (Bosse, 2010; Osler, 2011; De Melendez \& Beck, 2018; Arsal, 2019). Primarily, this is important to analyse the specificity of the sustainability conception within the multicultural process.

Sustainability conception is a systemic approach that helps to see the new perspectives in education (Fisher \& McAdams, 2015; Bosse, 2010; Hoehmann, 2011). The researchers believe that at first, the theoretical analysis should be supported by recent work discussing the influence of the sustainability conception on the process of multicultural teaching within regional policy.

The process of developing multicultural teaching and education is a long process that emphasises the synthesis of various movements throughout a variety of educational practices.

Recent literature (Bertelsman, 2010; Holzinger \& Knill, 2005) concerning the problem recognises the existence of sustainability conception and begins to explain the reasons for its persistence or not in the educational process as a complex phenomenon.
Second, in attempting to explain the necessity to understand that one discipline cannot offer valuable support for systemic change towards sustainability in teaching, different theoretical approaches relate the maintenance of integrative forms of cooperation to a number of variables connected with efficiency and the capacity to innovate and gain knowledge in the new multicultural environment (Kang, Kim \& Park, 2019). Throughout the analysis of the problem of sustainability conception development within multicultural processes, researches have advocated further views:

- Holistic and value-based methods: the new research sustainability conception has demonstrated the complexity of sustainability conception (Hartmann, 2018; Rasmussen, 2009). Sustainability science operates under the underlying assumption that significant measures are needed to ensure the long-term use of our planet. Besides, this science is promoting a fair distribution of resources among current societies. The majority of countries examine new pedagogical movements through the perspective of historical frames of reference in the study of education as well as multicultural teaching (Hoehmann \& Zhukova, 2012). To accomplish this, it is important to use the approach that helps to witness the varieties of educational systems altogether. The lack of systemic or unified research in the field of sustainability conception development within multiculturalism has reduced new strategies of communication to the simple implementation and integration between educational practices. The interest in the comparative researches to develop new strategies for education implementation within multiculturalism was the motivation of the study when comparative research is a significant contributor to educational theory and practice in many countries. 
- Inter- and trans-disciplinary methods: by its nature, sustainability conception is inter- and transdisciplinary signalling that this conception brings together multiple disciplines in order to understand complex systems from multiple perspectives (interdisciplinary). It is also necessary to understand here that 'sustainability' conception is capable of integrating both academic disciplines and the varieties of practices of educational policymakers, and education staff in the educational process. Nowadays, integration is developed on many levels: state, regional and local. It is essential to review the specifics of each level and identify opportunities for the development of further scientific research at each level. We believe in the positive view on the process of integration. The development of new ideas in education is important and necessary for the current climate of the multi-culturally-sensitive educational institution and individualities. As can be seen from the researches concerning the new views to multicultural teaching (Mensah et al., 2018), it remains paramount to assess different tasks for students that focus on the series of information gap tasks.

- Action-oriented and reflective methods: researchers in this field (Fleischer, Leutner \& Klieme, 2012) are asked to be critical of their impact and to acknowledge their responsibility for acting either against or for sustainable development. Moreover, sustainability conception is oriented to observe and accumulate the necessary knowledge. Some researchers believe that sustainability conception seeks to create a variety of changes toward more sustainable development of the theory of multicultural teaching and education and its role in the modern world (Göbel \& Hesse, 2009), which is indeed important to understand that all dimensions in cultures are interrelated, but each needs attention to detail and focus. Introducing different cultures in a social studies class does not satisfy multicultural teaching. Today, an integrative educational model is a significant contributor to educational theory and practice in many countries.

Furthermore, we also wanted to investigate how the integrative model could be applied to the current multicultural dynamics in regions. The authors believe this model provides a new view on a variety of methodological and technological aspects. The research, therefore, has three objectives. There must be a systemic description of the processes in the development of the integrative model.

- In the first stage, it is critical to examine how the sustainability conception result is conceptualised and related within the values native to one's own regional educational policy in the multicultural society. We believe it is essential to explore some studies which address the problem by discussing theoretical questions behind the role of the sustainability conception to multicultural teaching within the regional policy;

- In the second stage, it is necessary to discuss and criticise technologies and methods that draw from empirical studies. Here, we think it is essential to explore what technologies are relevant to communicate, cooperate and collaborate between different societies in the world.

- In the third stage, attention should be focused on solving those problems associated with the development of the multicultural-style concept in regional education (here; the research data is analysed from a study conducted at the Samara State University of Social 
Sciences and Education and German (Ludwigsburg Pedagogical University).

The research has four sections following this introduction, wherein we have discussed the issues in the current situation to investigate how sustainability conception could be applied to the multicultural dynamics in regions. In the next section, we present the analysis of the current methods deployed in this research. Following this, we present a brief history of the studied sector, focusing on the recent views on the problem after changes (holistic and value-based methods, inter- and transdisciplinary methods and action-oriented and reflective methods). This is important to investigate how the sustainability conception in education is perceived (especially on the example of Russian and German educational environment). This section is followed by a

model of possible ways to facilitate the process of cooperation and collaboration within the problem of the integrative model development between Russian (Samara State University of Social Sciences and Education) and German (Ludwigsburg Pedagogical University) Universities in future.

Finally, in conclusion, the paper offers some final remarks on the current research.

\section{Methodology}

\section{Research Design}

For this research, we chose the structural and functional approach to understand the methods and technologies to aid in the development of the integrative model towards sustainability conception within multicultural processes in regions. This approach helps to analyse the functions of every unique environment that influence teaching (Alismail, 2016). This approach aims to see sub-environments specificities and their role in educational environment development. We describe three sub-environments levels (individuality-oriented research level, region-oriented research level and country-oriented research level).

\section{Sample}

It is necessary to consider a case study when the researcher aims to explore a single entity or phenomenon to collect new information during a sustained period. As stated above, here we analyse the educational practice of two regional higher institutions (Samara State Pedagogical University and Ludwigsburg Pedagogical Institute). This method aims to promote collecting, presenting and analysing the subject.

\section{Research Limitation}

We, however, believe that the primary research limitation of the current study concerns the lack of new and up-to-day statistical data about the specificity of integration processes in regions and countries (Germany and Russia).

\section{Results}

\section{Sustainability Conception and Cooperation Process in Educational Systems Development}

Sustainability means the capability to sustain. That is a state position that can be maintained at a certain level. Sustainability often refers to the continued ability of a system to provide us with the resources that we need to live a comfortable and satisfying life. Moreover, it is essential to mention that sustainable development is ultimately a social choice about what to develop, what to sustain, and for how long. The Board on Sustainable Development of the National Research Council describes the transition to sustainability as the necessity of meeting the needs of stabilising the future world. Sometimes identified solutions may have incomplete, contradictory, and changing requirements. That comes as the natural, social, and human systems interact in complex ways and that it is becoming increasingly critical that those interactions should be understood better.

Recent literature concerning the problem recognises the existence of multi-scalar, multifaceted, and strongly interrelated sustainability challenges and begins to explain the reasons for its persistence in the educational process. In this sense, the sustainability conception is an academic educational area, which is trying to target these sustainability challenges. Moreover, 
the authors believe that the current view, emerging from a lively and ongoing discussion, sees knowledge production in sustainability science as an integration of three different types of knowledge - system knowledge: analytical, explanatory and systemic; transformative knowledge (supporting transformations) and action-guiding visions (target knowledge, normative, anticipatory, orientation-guiding, and goal-setting).

- The first knowledge type helps to create a current view of how a system of multicultural teaching is functioning with unsustainable patterns. For this purpose, it remains paramount to describe the system so that scientists can agree with relevant current views on what is dysfunctional in education within multiculturalism. Does it exist? If yes, then what is wrong about it? Do the processes of cooperation and collaboration between the countries and the work of the region?

- Transformative knowledge is about how to create effective change in the system. The systemic thinking inherent to sustainability conception would need to consider the co-evolution of knowledge and experiences regarding how to support change in the system. An important question here is how we can develop transformative knowledge of how to develop teaching within multiculturalism and make it useful for other cases as well. Transformative knowledge is very action oriented. Participation (both students and teachers) plays a central role. If we manage to make the research process, an intrinsic change process through action and reflection, we can promote scientifically supported changes. What are the methods and technologies to develop the process of cooperation and collaboration between countries? How will they influence to develop a model in a region within multiculturalism?
- The last knowledge type is devoted to the result of a negotiation process to provide a sustainable conception within multiculturalism. This is an ultimate vision of how sustainable development could look like- what are the methods and technologies to improve the processes of cooperation and collaboration between regions?

- Why are we trying to satisfy particular current views that do not actually contribute to our goal? How can we effectively engage people (both teachers and students) in the process of cultural integration which can help to provide the process of multicultural teaching and education development? How can countries comprehend the complexity of the problem in order to take their further actions? These are the issues which are essential to investigate.

\section{Sustainability Conception and Information Gap Tasks}

For the last decades, the school and the university disciplines have had a unique perspective and essential knowledge to contribute the relevant multicultural education.

We believe that this is partially due to the tension between the standards and expectations for pedagogical researches and the nature of sustainability challenges for this period. Thus, in this research, an attempt has been made to demonstrate the decision about how to close the gap between their preservice curricula and teachers' and students' beliefs and attitudes, in particular, considering multicultural teaching. Below we give the examples of information gap tasks which help to integrate the views on the problem by many people with different cultural backgrounds.

\section{Information gap task 1}

Answer Key. Sustainability conception is the critical aim of modern education. Can you identify ways to improve this process? 
Task. Make an online project about the role of sustainability conception, in particular, consider multicultural teaching.

\section{Activities.}

- Review the literature on the problem of sustainable development and its role in multicultural teaching development.

- Give teachers and students of different regions a mini-questionnaire related to the problems they have.

- Think of the further actions and the ideas to adapt to your country or the region you live in.

\section{Information gap task 2}

Answer Key. Although there is a growing interest in the importance of sustainability conception development in a region, there is still a lack of theoretically well-grounded studies in different countries. The teacher is not ready to organise and support regional curricula.

Task. You lived and worked in the Muslim part of the country. Then you moved to live in and

work to the Christian part of the country. You understand you do not know how to organise your work with children with other multicultural backgrounds and preferences.

- Review the literature on the problem of regional police in education.

- Analyse the teaching practice in schools in different countries.

- Work in groups and share your views on how to develop a regional educational environment.

- Do an online project.

\section{Sustainability Conception and Integrative Model of Multicultural Teaching}

The authors of the research paper believe that an integrative model involves a set of human resource activities towards improving and enhancing the achievement of the sustainability conception goals. This model is typically carried out by the government of the country and is aimed at optimising people's motivation to better understand different cultures, development and efficiency on both individual and peoples' levels (Sung et al., 2016). We believe that sustainability conception must be adjusted to individuals' requirements and every country's law and view on the process of cultural integration (Sorokin, 2017). For this reason, multicultural models in regions and variations should be described.

The accomplishment of multicultural teaching goals has a critical influence on training and development. Besides, this teaching provides great adjustment tools for both individuals and team working. Thus, the sustainability conception needs to be organised in a very gentle and balanced way. As literature review confirms, the model of multicultural teaching should consider a set of factors connected with work output, later productivity and effectiveness, which is the most required norm of the current climate (Estrada \& Matthews, 2016).

The first group of factors below is related to the development of a multicultural curriculum for teachers with different academic specialisations. Organisations responsible for teachers' education should be prepared to aid in the review and development of a multicultural educational curriculum for student and teachers.

The factors of the second group are connected with assessing multicultural teaching and assisting in its creation. The goal in integrating various educational systems is to find collaborative ways to improve coaching, mediation and evaluation in regions.

Thus, this model needs a solid foundation for further activities and their implementations:

- the development of every individuals' motivation and capabilities to enlarge knowledge about the varieties of cultures; visions, missions, values and strategies in different regions must be adapted to individuals; capabilities and knowledge must be developed to create a working relationship and better feedback system between both individuals and educational institutions; 
- the secure link between the model of multicultural teaching in a region and sustainability conception;

- feedback between different regions should be taken into account regularly.

Taking these factors into account, we tried to develop the integrative model, which could be applied to the current multicultural dynamics in regions. An existing model in regions may hold a critical locational asset to the environment, insofar as the option of a new model may be in a much less profitable location. It is expected that there will be a continuing instability of sustainable forms, reflected in the movement to initiate cooperation between universities in different regions and countries. There must be a systemic description of the processes which incorporate the logic of comparative research (which focus on differences between timelines for the development of international education in different countries, geographic differences, and the rate at which countries could work towards interdependence).

Further changes entailed are:

- Individuality -oriented changes which refer to the principles of students environment functioning. Thus, it is imperative to speak about individual effectiveness development. Tolerance, capacity, capability, systems and processes refer to strategic intent and mission, which determines the way they orient their activities (Merleau-Ponty, 2015). Moreover, it also specifies how resources and know-how will be used in order to achieve those presumptions.

- Regions - oriented participatory changes, which refer to the decisionmaking system. This change will influence the tolerance oriented system development, in particular, considering division into small units, management of those units which can support the sense of management and responsibility, sense of attainment which can quickly replay to dynamic multicultural environment changes in regions (Chryssochoou, 2000).

- Country-oriented changes integrate internal resources and external environmental information. These changes strategies are just an overall direction for the whole country that emphasises its structures, resources, staff and prospects, advantages and disadvantages of the integrative model. The fundamental process begins with the classification of the present education state by putting all strategically useful information into a single framework (individuality and regions).

Below we present the model of changes (see Figure 1).

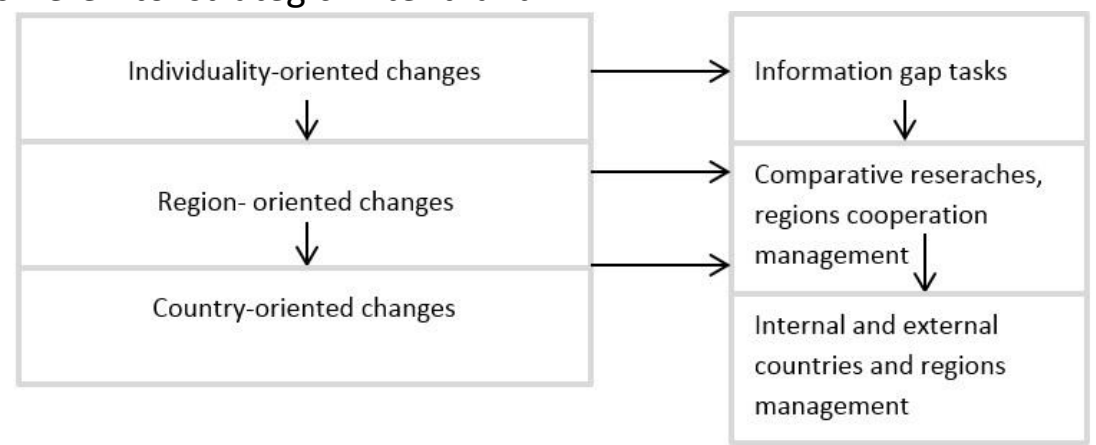

Figure 1: Multicultural Teaching in Regions Source: Created by the Authors

\section{Discussion}

Although there is a growing interest in the cooperation mentioned above and integration, there is still a lack of analysis of the possible models of further collaborations between the countries. 
The studies of two universities in Germany and Russia strongly believe that it is essential to consider the further methods and technologies of integration and describe the further aspects individually-oriented changes policy in education, region-oriented policy in education and country-oriented changes in education (Pereverzeva \& Shamne, 2017).

\section{Stage 1: Individually-Oriented Changes Policy in Teaching}

This stage demonstrates the importance of the formation of tolerance, of awareness of and responsibility for the values of social and cultural identification, and readiness to create the sustainability model of multicultural teaching. Several scholars (Bosse, 2010; Hosseini Fatemi, Khajavy \& Choi, 2016; Kokarevich \& Sizova, 2015; MacDonald \& O'Regan, 2013) have demonstrated the role of tolerance in intercultural communication, through which we confirm the importance of the further aspects of what?? clarity. Scientists in education believe that we have to spend more time looking for links between the specific characteristics and integrative characteristics of tolerance and convert them into psychological, language and pedagogical aspects.

The research on aspects influencing the psychological problems of native people and immigrants have demonstrated those characteristics - cultural and social isolation at schools and higher institutions led to problemsas feelings of grief and mourning, misunderstanding, helplessness, anxiety, depression and pessimistic thoughts; low social status at school and higher institution within the new multicultural society; feeling of being stigmatised exacerbated the participants' sense of incompetence(Bertelsman, 2010; Van Vught, 1996; Lanfranchi, 2008; McLaren, 2018). Besides, traditionally accepted roles of men in eastern families and women in western countries further add to the already existing psychological problems s (Bertelsman, 2010; Van Vught, 1996; Lanfranchi, 2008; McLaren, 2018).

Moreover, people face a definite language barrier. They experience an emotional breakdown at the isolation of being surrounded by those whose language is alien to them or not been understood both by native speakers and immigrants. Problems in speaking and understanding the foreign language make it difficult to re-establish in the new environment (see, Biserova \& Shagivaleeva 2019; Fayzullina, 2019). Thus, scientists consider this as a big problem (Freire \& Valdez, 2017; Mamedov, 2009).

Pedagogical problems concern the new educational environment. Students usually demonstrate problems facing educational policies and practices; adjustment of structures of education bearing in mind cultural differences within the new educational and multicultural environment and the overall cultural climate in class; varieties in curriculums and the new curriculum planning (Bode, 2008; Nieto et al., 2008).

\section{Stage 2: Region-Oriented Changes Policy}

In Russian and German regions (Samara region and Baden-Wuertemberg), multicultural teaching models are overlooked and underestimated. Russian and German regions with multicultural background require the new views and the technological changes to sustainability conception development within multiculturalism. We believe that we have to spend more time looking for links between regional educational levels.

Similarly, it is essential to examine both the cultural values and the representation of those values, the specificity of the multicultural background and the prospects of the new multicultural educational environment in regional development and further implementation (Luijten-Lub, van der Wende \& Huisman, 2005; Palatkina, 2007). Local cultures are changing and are combining with others in new and unusual ways. However, there is a lack of research concerning the statistical data which reveal the current situation in the regions.

Analysis of the educational policies in higher education of the two above mentioned regions and the universities unfolds the importance of researches concerning structure of higher 
institutions, assessment of teaching approaches to multicultural teaching and education; traditional teaching approaches and pedagogical models; national curricula; academic subjects; readiness amongst teachers and students to foster positive classroom climate; scientific researches on: (professional education, multicultural education, multicultural education within integration and globalisation, sustainability conception in education) (Göbel \& Hesse, 2009; Kajikawa, 2008; Parris \& Kates, 2003).

\section{Stage 3: Country-oriented Changes in Education}

The main attribute that defines the educational model structure is asset specificity, which is present in cooperation and collaboration between regional educational models and absent in those occurring. Thus, in order to facilitate the integration of different educational systems around the world (between Russia and Germany within the current research), institutions of higher education should work towards a unified selection of educational models, programs, approaches and technology to use in each university's own curriculum (Hartmann, 2018; Bosse, 2010). To do so, it is important to provide further ideas to consider, that is, the analysis of traditional teaching approaches which must be reconstructed to examine how they contribute to and support national curricula; the analysis of national educational systems, which must be presented from diverse cultural preferences and perspectives; readiness among countries to integration to foster a positive attitude to education and teaching within multiculturalism; to examine educational institutions administrative process in order to assess whether an institution offers a consistent program to develop multicultural education and teaching within sustainability conception (Vargas, 2000).

\section{Conclusion}

Considering the problem concentration of the set of a model, it is evident that the notion of sustainability bears immense importance. We believe in the idea of essential requirement, which allowed regions to build a multicultural model within sustainability conception. We suggest the following methods: holistic and value-based; inter- and trans-disciplinary; action-oriented and reflective methods. The majority of the barriers result from the lack of comparison researches. Given the information presented above, we analysed results from Samara State University of Social Sciences and Education and Ludwigsburg Pedagogical Institute. The findings suggested that there is an increasing focus on transforming multicultural education, which leads the need for a new integrative model of teaching in regions. We, therefore, suggest for a model focused on improving the process of multicultural teaching in regions. By analysing how the presented model would work in both countries, it is possible to determine stages that should become the basis of the model of multicultural teaching. In conclusion, we can confirm that the research has demonstrated that multicultural teaching is a sustainable matrix of the three stages (individuality-oriented, regions- oriented and states-oriented) and views that show new strategy on the theories.

\section{References}

Alismail, H. A. (2016). Multicultural Education:

Teachers' Perceptions and Preparation. Journal of Education and Practice, 7(11), 139146.

Arsal, Z. (2019). Critical multicultural education and preservice teachers' multicultural attitudes. Journal for Multicultural Education, 13(1), 106-118.

Bertelsman, S. (2010). Making lifelong learning tangible. Gütersloh, pp. 77-78.

Biserova, G., \& Shagivaleeva, G. (2019). SocioPsychological Adaptation of International Students to Learning and Professional Activities. Journal Space and Culture, India, 6(5), 99-114. https://doi.org/10.20896/saci.v6i5.411

Bosse, E. (2010). Vielfalt erkunden - ein Konzept für interkulturelles Training an Hochschulen. Schlüsselqualifikation interkulturelle 
Kompetenz an Hochschulen. Grundlagen, Konzepte, Methoden. Wiesbaden: VS Verlag für Sozialwissenschaften, pp. 109-133.

Burns, R. J., \& Welch, A. R. (2018). Contemporary perspectives in comparative education. Routledge.

De Melendez, W. R., \& Beck, V. (2018). Teaching young children in multicultural classrooms: Issues, concepts, and strategies. Cengage Learning.

Duzhakova, M. (2008). Development of teacher education in a multicultural society: a monograph. Voronezh, $225 \mathrm{p}$.

Estrada, F., \& Matthews, G. (2016). Perceived Culpability in Critical Multicultural Education: Understanding and Responding to Race Informed Guilt and Shame to Further Learning Outcomes Among White American College Students. International Journal of Teaching and Learning in Higher Education, 28(3), 314-325.

Fayzullina, O. R. (2019). Ways of International Students' Adaptation: Club of International Friendship. Journal Space and Culture, India, 6(5), 87-98, https://doi.org/10.20896/saci.v6i5.412.

Fisher, P. B., \& McAdams, E. (2015). Gaps in sustainability education: The impact of higher education coursework on perceptions of sustainability. International Journal of Sustainability in Higher Education, 16(4), 407-423.

Fleischer, J., Leutner, D., Klieme, E. (2012). Modellierung von Kompetenzen im Bereich der Bildung. Eine psychologische Perspektive [Special issue]. Psychologische Rundschau, 63(1).

Freire, J. A., \& Valdez, V. E. (2017). Dual language teachers' stated barriers to implementation of culturally relevant pedagogy. Bilingual Research Journal, 40(1), 55-69.

Göbel, K., Hesse, H.G. (2009). Interkulturelle Kompetenz - ist sie erlernbar oder lehrbar? Konzepte für die Lehrerbildung, die allgemeine Erwachsenenbildung und die berufliche Weiterbildung. Handbuch der Erziehungswissenschaftenn. Band III/2. Paderborn. Schöningh Verlag, pp. 1139-1152.

Hartmann, E. (2018). Overburdening Higher Education? The Europeanisation of the Professional Complex. In European Higher Education and the Internal Market (pp. 287308). Palgrave Macmillan, Cham.

Hochschulen in Brandenburg. Ergebnisbericht, CHE Working Paper, Gütersloh, 51.

Hoehmann, K., Zhukova, T. (2011). Teaching sociocultural qualities in German and Russian universities. The current problems of teaching the future teachers and the ways of professional competence development, PGSGA, pp. 26-30.

Holzinger, K., Knill, C. (2005). Causes and conditions of cross-national policyconvergence. Journal of European Public Policy, 12(5), 775-796.

Hosseini Fatemi, A., Khajavy, G. H., \& Choi, C. W. (2016). Testing a model of intercultural willingness to communicate based on ethnocentrism, ambiguity tolerance and sensation seeking: the role of learning English in Iran. Journal of Intercultural Communication Research, 45(4), 304-318.

Kajikawa, Y. (2008). Research core and framework of sustainability science. Sustainability Science, 3, 215-239.

Kang, H. S., Kim, E. J., \& Park, S. (2019). Multicultural teaching efficacy and cultural intelligence of teachers: the effects of learning goal orientation and training readiness. International Journal of Educational Management, 33(2), 265-275.

Kokarevich, M. N., \& Sizova, N. Z. (2015). Model of tolerance of intercultural communication. Procedia-Social and Behavioral Sciences, 166, 621-625.

Lanfranchi, A. (2008) Interkulturelle Kompetenz als Element pädagogischer Professionalität Schlussfolgerungen für die Lehrerausbildung. 
Interkulturelle Kompetenz und pädagogische Professionalität. Wiesbaden, pp. 231-260.

Luijten-Lub A., M. van der Wende, Huisman, J. (2005). On cooperation and competition: A

MacDonald, M. N., \& O'Regan, J. P. (2013). The ethics of intercultural communication. Educational Philosophy and Theory, 45(10), 1005-1017.

Mamedov, N. (2009). Sustainability development conception - up to date view on the conception. Education and sustainability conception, Saint-Petersburg, pp. 72-88.

McLaren, P. (2018). Revolutionary multiculturalism: Pedagogies of dissent for the new millennium. Routledge.

Mensah, F. M., Brown, J. C., Titu, P., Rozowa, P., Sivaraj, R., \& Heydari, R. (2018). Preservice and inservice teachers' ideas of multiculturalism: Explorations across two science methods courses in two different contexts. Journal of Science Teacher Education, 29(2), 128-147.

Merleau-Ponty, M. (2015). The Cultural Limits of Legal Tolerance. Law's Religion: Religious Difference and the Claims of Constitutionalism, 105.

Nieto, S., Bode, P., Kang, E. \& Raible, J. (2008). Identity, Community and Diversity: Retheorising multicultural curriculum for the postmodern era. In F. M. Connelly, M. F.He, \& J. Phillion (Eds.), The Sage handbook of curriculum and instruction, $225 \mathrm{p}$.

Osler, A. (2011). Teacher interpretations of citizenship education: national identity, cosmopolitan ideals, and political realities. Journal of Curriculum Studies, 43(1), 1-24.

Palatkina, G. (2007). Multicultural education of young people throughout Russia. comparative analysis of national policies for internationalisation of higher education in seven Western European countries. Journal of Studies in International Education, 9(2), 147-163.

Multicultural education of youth: the principle of ethnic tolerance: monograph. Astrakhan, $128 \mathrm{p}$.

Parris, T. M., Kates, R. W. (2003). Characterising a sustainability transition: Goals, targets, trends, and driving forces, Proceedings for the National Academy of Sciences, 100(24), 8068-8073.

Pereverzeva, Y. V. \& Shamne, A. N. (2017, November). Financing higher education: experience of Russia and Germany. In 7th International Scientific and Practical Conference "Current issues of linguistics and didactics: The interdisciplinary approach in humanities"(CILDIAH 2017). Atlantis Press.

Portera, A. (2008). Intercultural education in Europe: epistemological and semantic aspects. Intercultural Education, 19, 481-491.

Rasmussen, P. (2009). Lifelong learning as social need and as policy discourse. Oxford: Symposium Books, pp. 5-100.

Sorokin, P. (2017). Social and cultural dynamics: A study of change in major systems of art, truth, ethics, law and social relationships. Routledge.

Sung, Y., Lee, J. A., Kim, E., \& Choi, S. M. (2016). Why we post selfies: Understanding motivations for posting pictures of oneself. Personality and Individual Differences, 97, 260-265.

Vargas, C. M. (2000). Sustainable development education: Averting or mitigating cultural collision. International Journal of Educational Development, 20(5), 377-396. 